\title{
CONTEMPORARY STRATEGIC INNOVATIONS IN THE INDIAN MEDICAL INDUSTRY - A DESCRIPTIVE APPROACH TO PROBLEM
}

\author{
AGNIESZKA CHRISIDU-BUDNIK* \\ ALEKSANDRA SUS**
}

\section{INTRODUCTION}

Joseph A. Schumpeter was a pioneer of research on innovation in enterprises. The concepts that he introduced are still discussed by contemporary theorists and practitioners. The already classic combinations of production factors, such as new products, production methods, raw materials, markets, and industry organizations ${ }^{1}$, are currently assuming completely different forms because they also take into account the soft sphere, i.e. social sphere, which was disregarded by the Schumpeterian school of thought which rather focused on the technical aspects of innovation. Schumpeter's theory was formulated in a capitalist economy at the beginning of the 20th century. This economy was based on large, massive and concentrated industry where land, labor and capital were the most important resources. The dynamic imbalance that was created by entrepreneurs has remained unchanged. This imbalance is the backbone of a market economy to a greater extent than equilibrium and optimization are ${ }^{2}$.

Analysis of changes that have occurred in recent years in the broadly defined process of managing organizations demonstrates important trends in creative destruction. These changes are not only connected with the emphasis that is placed on introducing technological innovations, which is the main trend in the revival of enterprises, but also with changes in the perception of the sources of these innovations. The environment of contemporary organizations seems to be a new source of innovation, which results in the emergence of open innovations. Value innovation, which was

DOI: $10.1515 /$ wrlae-2015-0013

* PhD, Assistant Professor of Management and Administration Science, Institute of Administrative Studies, University of Wrocław, agatex@prawo.uni.wroc.pl

** PhD, Assistant Professor of Management Science, Institute of Organization and Management; Wrocław University of Economics, aleksandra.sus@ue.wroc.pl

${ }^{1}$ Joseph A.Schumpeter, The Theory of Economic Development (Harvard University Press 1934) .

${ }^{2}$ Ireneusz Bielski, Przebieg i uwarunkowania procesów innowacyjnych (OPO 2000). 
popularized by W.Ch. Kim and R. Mauborgne, considerably reorganizes the functioning of organizations, and simultaneous monitoring of the environment for disruptive innovations increases the probability of achieving organizational success. However, are these conditions sufficient to achieve this success, especially since production activity is gradually disappearing in, for example, Poland, while newly-formed companies generally deal in services? Is the Japanese lean management turning into lean services?

The aim of this article is to present innovative activity in the medical service sector. Innovation is often reduced to the development of technologies. This development undoubtedly contributes to improvements in the process of providing medical services, and consequently also in health and life expectancy, but relatively little importance is attached to soft innovation. Meanwhile, all innovations are introduced in order to improve the condition of humanity. Whether potential sources of innovation are identified and whether innovations are implemented effectively depends on individuals' proper functioning, inquisitiveness and axiology as well as knowledge and skills. The aim of this article will be achieved by undertaking a case study of Dr. Devi Shetty's chain of clinics.

\section{STRATEgiC CONTEXT OF CONTEMPORARY INNOVATION}

As has already been mentioned, contemporary innovations take different forms. Given their strategic dimension, it seems that value innovations, open innovations and disruptive innovations are the most important among them. These types of innovations are situated within an enterprise's strategic dimension because they influence the business model that has been adopted in a given company, and their identification and application requires using strategic resources, in particular non-material ones such as knowledge and relational resources. They also play a very important role in the process of creating new markets and new forms of competition which are not necessarily related to market and product or technological innovations.

Various determinants of strategic innovations are pointed to in the literature on the subject. On the one hand, their role in the process of changing the existing business model in order to create new value for customers, and consequently to surprise the competition and generate above-average profits for all stakeholders, is emphasized ${ }^{3}$. On the other hand, these innovations are seen as a dramatic change in the business game played out in existing markets, which is based on the identification of gaps in the sector, new market segmentation and continuous experimentation ${ }^{4}$. The importance of the purposeful orchestration and placement of nonmaterial resources, especially knowledge and skills, is also emphasized. In

\footnotetext{
${ }^{3}$ Gary Hamel, 'Strategy as Revolution' (1996) 74 Harvard Business Review 69-82; Gary Hamel, 'Strategy Innovation and the Quest for Value'(1998) 39 Sloan Management Review 7-14.

${ }^{4}$ Constantinos C. Markides, 'Strategic Innovation in Established Companies' (1998) Sloan Management Review 2; Constantinos D. Charitou, Constantinos C. Markides, 'Responses to Disruptive Strategic Innovation’ (2003) 44 Sloan Management Review 55-63.
} 
this respect, the management of strategic innovation covers three areas: a) entrepreneurial (related to products and the market), b) engineering (technological) and c) executive (defining directions in the innovation domain) $)^{5}$.

Interestingly, R.E. Johnston and J.D. Bate, who follow H. Mintzberg's train of thought, do not equate strategy innovation with strategic planning. According to these authors, the analytical, disciplined processes of strategic planning, which are carried out based on periodic comparisons of hard data and facts, have nothing to do with creating an innovative business strategy. This is because such a strategy should be creative and intuitive rather than analytical and logical - it should focus on insightful observations of market entities that are not only connected with an organization. It is important to analyze one's customers' and business partners' words, emotions, gestures and wishes, i.e. details which a hard planning process does not take into account. Additionally, a strategically innovative organization is oriented toward the market, not toward the company. By using the Copernican heliocentric model in which the sun is the center of the universe as a metaphor for an organization, one may say that organizations should stop placing their companies at the center of the business space-time continuum. An enterprise is one of the planets rather than the sun - neither suppliers nor customers revolve around an enterprise, and therefore it should focus on meeting their needs. Thus, a symbiosis between particular elements of the market, i.e. their functioning for their mutual benefit, is the key to the success of an innovative strategy. As a result of identifying business opportunities, enterprises provide significant added value to their customers, thus obtaining a financial surplus in return. The final element that makes strategic innovations different from strategic planning is that the former take into account heuristic problem-solving methods, which makes them flexible. Therefore, the focus is on creating new value in new markets, which puts strategic innovation before strategic planning processes. This is a somewhat interesting conclusion, which is also confirmed by the analyzed case presented below.

\section{Strategic Dimensions of InNOVATION}

Generally speaking, any purposeful activity that leads to a change in the current state of objects and/or relations between them can be regarded as an innovation. Continuous revival, i.e. continuous adaptation to the changing needs of particular elements of the environment as well as to the changes in their configuration, is a requirement that is currently imposed on organizations. Strategic transformations force organizations to adopt new attitudes and trigger new kinds of reactions; among such reactions are value innovations, open innovations and disruptive innovations, which are dealt with in this article.

\footnotetext{
${ }^{5}$ Martyn Pitt, Ken Clarke, 'Competing on Competence: A Knowledge Perspective on The Management of Strategic Innovation' (1999) 11 Technology Analysis and Strategic Management 301-316.
} 
Value innovation is a new way of thinking about the general strategy of an organization whose main goal is to achieve a competitive advantage and give added value to its customers. This involves redefining a mature business model and also redesigning the elements of entities that participate in the market game as well as the relations between them ${ }^{6}$.

The process of value innovation is carried out in the domain where a company's activities are focused on minimizing costs while at the same time meeting the requirement that new value be delivered to customers. This is possible by offering customers such products or services that were not provided by a given sector before, whereas costs can be limited by eliminating factors that generate competition. Cost reduction, which is a part of the new approach to competition, is achieved as a result of applying economies of scale, which in fact is another source of value, this time also for the organization itself, and not only for its customers. This is why value innovation has become an integral part of blue ocean strategy.

According to the classic approach to competitive strategies, sector boundaries are fixed and rigid and competitors compete with one another in a given, predetermined area. Also, the set of tools used in the competitive struggle is finite, whereas managers' creativity is only apparent, as evidenced by the increasingly sophisticated "promotions of promotions", commercialization of emotions and feelings or slogans such as "even higher quality". To top it all, CSR practices are becoming increasingly more common among companies in such red oceans today. Attractive as they might seem within an overall organizational strategy, such practices have only one goal, i.e. to consolidate the positive image of a company among local communities, which leads to maximizing sales, and consequently to increasing profit.

W.Ch. Kim and R. Mauborgne demonstrate that competition within a given industry, both with regard to companies and customers, does not have to be based on Boolean logic. This can be seen from the examples of Cirque du Solei, which was extensively described by the aforementioned authors, and of NetJets, Novo Nordisk, HBO, Pfizer or Starbucks. All of these organizations succeeded in changing market boundaries by reconstructing the vision of their own strategies as a result of endogenous growth. Thus, history has come full circle. This is because these strategies refer to the observations made by Schumpeter, as mentioned above, in whose opinion innovations occur as a result of changes in the factors within a system, while their basic source is the creativity of the entrepreneur ${ }^{7}$.

By using deductive thinking, one can justify the assertion that value innovation represents the broadest concept within the strategic dimension of innovations. While having regard to the special nature of value innovations, one should think where to look for their sources. Open innovation is a concept which has changed companies' approach to innovative activity and which may provide a foundation for value innovation. This is a relatively new concept which has not yet been fully recognized in the world of

\footnotetext{
${ }^{6}$ Paul Matthyssens et.al., 'Innovation. Value Innovation in Business Markets: Breaking the Industry Recipe' (2006) 35 Industrial Marketing Management 751-761.

${ }^{7}$ W. Chan Kim, Renee Mauborgne, Blue Ocean Strategy (Harvard Business School Press 2005).
} 
management ${ }^{8}$. The term was introduced by H. Chesbrough in 2003. Open innovation is the antithesis of the traditional, vertical innovation model, in which internal innovative activities lead to the internal development of products or services. H. Chesbrough refers to this model as the closed innovation model, and defines open innovation as a purposeful use of inflows and outflows of knowledge to accelerate internal innovations as a result of using market resources 9 . A change in an organization's orientation from the center toward the external environment does not mean that innovations within a company must be sacrificed. As a consequence, two kinds of open innovation emerge: outside-in and inside-out innovations. The former involves using external sources of knowledge, i.e. users, competitors, suppliers, partners and local communities (crowdsourcing), while the latter entails sharing existing internal knowledge with other entities which can then utilize it in their own activity. This model is much less recognized and understood both in academic communities and in business practice.

Contemporary organizations are actively seeking sources of innovation by going beyond the industries they have previously functioned in, thereby obtaining both material and non-material benefits ${ }^{10}$. However, the elimination of the NIH ("not invented here") syndrome is the most important benefit that can be derived from adopting the open innovation approach. This syndrome refers to a negative attitude among an organization's employees toward a novelty that was not created within their structures $^{11}$. The positive consequences also include the following: risk is reduced as a result of being spread across several entities; time and money can be saved; new relationship networks are created on the basis of coopetition and synergistic relationships.

As far as open innovations are concerned, the contemporary literature on the subject devotes the greatest attention to three topics: a) ways of measuring these innovations, b) interaction between an organizational strategy which is based on open innovation and the choices made by companies, and c) the increasing integration of the concept of open innovation with existing theories of innovation, management and economics $^{12}$.

\footnotetext{
${ }^{8}$ Eelko Huizingh, 'Open Innovations: State of the Art and the future Perspectives' (2011) 31 Technovation 2-9.

${ }^{9}$ Henry W. Chesbrough, 'Open Innovation. Where We're Been and Where We're Going' (2012) Research Technology Management 55.

${ }^{10}$ Peter C. Grindley, David. J. Teece 'Managing Intellectual Capital: Licensing and Crosslicensing in Semiconductors and Electronics' (1997) 39 California Management Review 836; Olivier Gassman 'Opening Up the Innovation Process: Towards an Agenda' (2006) 33R\&D Management 223-228; Ulrich Lichtenthaler, 'Open Innovation: Past Research, Current Debates, and Future Directions' (2011) 25 Academy of Management Perspectives 75-93.

${ }^{11}$ Keld Laursen, Ammon J. Salter, 'Open Innovation: the Role of Openness in Explaining Innovation Performance Among U.K. Manufacturing Firms' (2006) 2 Strategic Management Journal 131-150.

${ }^{12}$ Joel West et.al., 'Open Innovation: The Next Decade' (2014) 43 Research Policy 805 811.
} 
Disruptive innovation can become a specific tool for implementing open innovations. This kind of innovation involves monitoring emerging markets and newly created products as well as services or new applications of already existing products or services. Disruptive innovations concern companies that have managed to achieve a competitive advantage but were too weak to maintain this advantage for a long period of time. Companies such as IBM, Xerox, Bucyrus-Erie or Sears allowed their largest competitors to enter new markets while they themselves were focused on improving their products [sic]. For example, Dell Computer benefited from this state of affairs by implementing a new method of selling personal computers, i.e. directly to customers (1983); Amazon.com started using an on-line distribution system (for books in 1995 and for music in 1998); and Ryanair began rendering low-cost transport services (in 1991). Paradoxically, improvements made to existing products and their performance trajectories, which J.L. Bower and C.M. Christensen treat as a product's or service's performance improvement rate, turned out to be the main source of failure. Organizations ignore other values that can be important for customers by focusing on improving what they have already created and what they have invested significant financial resources in. This is how opportunities arise, which are used by the competition and which Bower and Christensen refer to as disruptive technologies. For example, IBM dominated the desktop computer market, thus creating a niche in the market for laptop personal computers. Sony created a market for mobile devices (it produced the model TR-63 pocket-size radio in 1957, which was the first radio of this kind to have been launched in the United States) by offering various new attributes such as small size, low weight and portability $^{13}$.

Disruptive innovations can be described through the prism of certain permanent properties that differentiate them from traditional products or services. At the beginning such innovations constitute a marginal part of the market and they do not directly compete with market leaders. These innovations are therefore unattractive until they begin to expand, i.e. until they capture a significant part of the market. Since certain organizations base their development strategy on other than traditional, i.e. disruptive, innovations, they also use different key success factors. In this way, a particular conflict occurs between the traditional ways of playing the market game and the new rules of this game. The following question therefore arises: should the enterprises that are threatened by this ignore disruptive innovations and follow the strategic path they have chosen or should they take account of such innovations in a separate department or enterprise? The most common reasons for which organizations decide not to implement solutions minimizing the effects of disruptive innovations are: a) the desire to follow the existing strategy and competitive path, b) the fact that they have invested too many resources in the present business, c) lack of permission from senior management to introduce changes, d) large problems with the existing business, as a result of which organizations do

\footnotetext{
13 Joseph L. Bower, Clayton M. Christensen, 'Disruptive Technologies "Catching the
} Wave" (1995) 73 Harvard Business Review 43-55. 
not have the time and resources to implement solutions that deviate from the strategy they have adopted ${ }^{14}$.

The same tools are used in open innovation as in disruptive innovation, only the elements that are observed are different. In respect of the former, a wide range of market elements are monitored, i.e. from suppliers and recipients to substitute products; regarding the latter, it is new products or services that are observed and attention is paid to areas that are ignored by the current market leaders.

Strategic innovations, which are dealt with in this article, are connected in a cause-and-effect relationship. By creating a specific pyramid, they constitute a deductive ladder that can be used to create a flexible organization, i.e. one that creatively responds to changes in the environment in real time (Figure 1).

Figure 1. Strategic innovation pyramid.

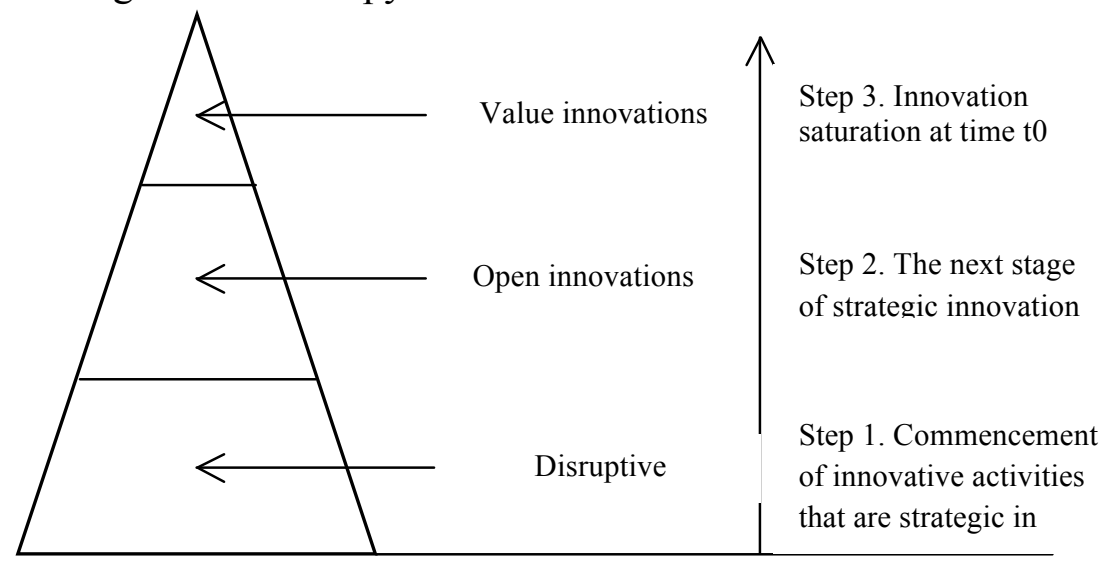

Source: Own work.

Innovation saturation refers to a full level of strategic innovation, which encompasses all of the pyramid's elements but which is not a finite set of innovative solutions and does not mean that an organization can stop carrying out activities in this area. Therefore, it is very important to identify the saturation level at a given moment.

All kinds of strategic innovations that are presented here can lead to innovations in saving, i.e. they can create an opportunity to increase the value that is offered to customers in exchange for minimizing the costs of a service. As has already been mentioned, this is possible by applying economies of scale, which is clearly illustrated by the example of Dr. Devi Shetty's chain of private clinics that is presented below. But what are the other factors that determine the success of lean services?

\footnotetext{
${ }^{14}$ Charitou, Markides (n 4) 53-63.
} 


\section{CAse Study}

An intrinsic case study is the research procedure that was used for the purpose of this article. This research tool was used because, unlike an instrumental or collective case study, it makes it possible to better understand the essence and character of a particular problem or feature. The case that is analyzed here is unique on a global scale and the aim of this study is not to create a theory, but to present a specific person and this person's innovative activity in the medical industry. Entrepreneurship and innovation are indicative of what people do and not of who they are. This case also represents a cohesive set of proactive and innovative behaviors that represent a sensible risk. These are additional arguments for using the selected research procedure.

Moreover, it should be emphasized that phenomenological studies are based on a naturalistic approach to the analyzed phenomena, and therefore they aim at an accurate description of reality. It is only possible to study highly variable phenomena in organizations by carrying out qualitative research, as "innovations occur in society only on the basis of irregularities, or deviations. One cannot learn anything about innovation processes by studying typical phenomena" ${ }^{\text {. }}$. The research method involved analyzing content obtained from various media, including the literature on the subject and the Internet, that was recorded in a way that made it possible to use inductive thinking, which in this case focused on answering the following question: what specific activities did Dr. Devi Shetty undertake in relation to managing a chain of private clinics which now allow us to discuss certain innovation patterns? Induction should be accompanied by deduction, mainly because induction itself does not make it possible to answer the question: why is that so? However, the aim of this study was not to establish causal determination.

\section{a) Introductory information}

In 1987, Daniel Callahan, an American philosopher and bioethicist, wrote a book titled "Setting Limits: Medical Goals in an Aging Society"16, in which he predicted current problems with providing medical services. These problems primarily amount to the disproportionately rapid increase in the cost of treatment relative to the lengthening of a human being's life. The anachronistic character of health care systems (the German health care system, which is the oldest in Europe, was introduced in 1883, when the average life expectancy was much lower), their financial and organizational inefficiency as well as the lack of a universal health insurance system in many countries are the main reasons why private health care systems are being developed all over the world. Attention should also be paid to three closely interrelated factors that determine the quality of life in a given country and the role that a private health care system plays there, i.e. the

\footnotetext{
15 Monika Kostera, Antropologia organizacji. Metodologia badań terenowych (PWN 2003).

${ }^{16}$ Daniel Callahan, Setting Limits: Medical Goals in an Aging Society. With a Response to My Critics (Georgetown University Press 1987).
} 
level of poverty in society, model of social insurance system, and incomeearning possibilities ${ }^{17}$.

Since India regained independence in 1947, life expectancy in this country has increased from 32 to 65 years, while the infant mortality rate has decreased by almost $70 \%$. Diseases such as smallpox, polio and dracunculiasis have been eradicated and the spread of HIV has been significantly reduced ${ }^{18}$. Despite all this, the health care system in India, which is the largest democracy and one of the largest economies in the world, is not able to provide its citizens universal and equal access to publicly funded health care services.

India has a very high population density of 1.2 billion people. By 2050 this number is likely to increase by 400 million. Currently, 350 million inhabitants of this subcontinent have to survive on less than two dollars a day. The duality that is characteristic of India is clearly manifested in the Indian health care system, like in the other spheres of life in this country. Theoretically speaking, the citizens of India can choose between the public and private health care sectors. In practice, however, access to public, free health care is very difficult to obtain because the supply of medical services is much lower than the demand for these services, while the level and standards of provided medical services are very low ${ }^{19}$. The rate of mortality from coronary heart disease is two or three times higher among Indians than Caucasians. One in four people die from heart disease. In India about 120,000 cardiovascular operations are performed, while the actual demand requires that at least about 2 million of such operations be carried out ${ }^{20}$. In the private health care sector the demand for surgeries of this kind is much higher. Currently, 69\% of the cost of medical services in India is borne individually by citizens and $93 \%$ of hospitals are private institutions, although only $8 \%$ of clinics were privately-owned in 1947 . About $80 \%$ of Indian doctors work in the private health care sector, which has $64 \%$ of hospital beds ${ }^{21}$. Private health care is characterized by high-quality and high-standard services that are provided by well-qualified physician specialists. The prices of medical services that are relatively low for the citizens of developed countries, high standards of these services and professional medical staff are three factors that have made the Indian private health care sector an important part of global medical tourism ${ }^{22}$. At the same time, limited access to the public health care sector for the citizens of India and the lack of a universal health insurance system leads to the extreme

\footnotetext{
17 Arnab Mukherji, Hema Swaminathan, 'The Role of Right to Health in Health Care Management and Delivery in India: In conversation with Dr Devi Prasad Shetty, Chairman, Narayana Hrudayalaya' (2013) 25 IIMB Management Review 28-35.

${ }^{18}$ A.K. Shiva Kumar, 'Confronting Health Challenges', in Bibek Debroy, Ashley.J. Tellis, Reece Trevor (eds), Getting India Back on Track: an Action Agenda for Reform (Carnegie Endowment for International Peace, Washington 2014).

19 Rajamani Subhashini, 'National Health Policy, The need of the hour: an Analysis in Indian Perspective' (2012) 25 Leadership in Health Service 232-248.

${ }^{20}$ Ketaki Gokhale, 'Heart Surgery in India for $\$ 1,583$ costs $\$ 106,385$ in U.S.', Bloomberg, 28 June 2013.

${ }^{21}$ Shiva Kumar (n 18) 53.

${ }^{22}$ Richard D. Smith, Rupa Chanda,Viroj Tangcharoensathien, 'Trade in Health - related services' (2009) 373 The Lancet $593-601$.
} 
impoverishment of almost 39 million of Indians a year (in the 21 st century!) because they have to finance the costs of private medical services themselves ${ }^{23}$. According to Amartya Sen, winner of the Nobel Prize in Economic Sciences, perhaps nowhere else in the world has "such a great economic development (brought) so little to the poorest sections of society" 24 .

The Wall Street Journal has called Devi Shetty, a cardiac surgeon and businessman, the "Henry Ford of heart surgery" because he uses the principles of mass production in medicine in order to drastically cut spending ${ }^{25}$. His goal is to carry out a health care revolution, which would be similar to the Industrial Revolution, so as to reduce the costs of health care while at the same time increasing its quality and efficiency. Dr. Shetty is creating a system for rendering medical services that offers a unique set of benefits to the patient for a lower price. At the core of this system lies the Cartesian body-soul dualism. Meanwhile, in the second half of the 20th century this theory was abandoned in medicine, and the holistic view of a human being's wellbeing was revived. The modern physician should not only care about the patient's body, but also about his/her mood and beliefs about health. The development of medical innovations (both technological and pharmacological ones) is one consequence of abandonment of the dualistic theory in medicine. This development has coincided with increased pressure on innovation and entrepreneurship in organizations, which first appeared in the United States. This change occurred very naturally in the US because Americans are highly inclined to take risks, and are individualistic as well as self-reliant ${ }^{26}$. As a result, a holistic concept of health care was developed which generated a demand for innovation. The pharmaceutical industry became particularly active at that time since it had an obvious financial interest in encouraging physicians to write prescriptions for their products as frequently as possible. There is no doubt that innovations contribute to increased health care quality. At the same time, one can observe with growing frequency that it is medical innovations which generate needs that then must be satisfied, and therefore it is medical innovations that are the basic cause of the enormous growth of health care spending [Ginzberg, 1990]. Americans, who place great emphasis on innovation, have calculated that if expenditures continue to grow as they have grown so far then the total budget of their country will be spent on treatment and health care by about the year 2080. Devi Shetty, who won The Economist's Innovation Award, states that "all the time new pills, injections and intricate, expensive equipment are invented, whereas what we need is innovation in the process of work itself". This cardiac surgeon creates a contrast between needs and costs in health care. Health care in industrialized countries is oriented toward needs rather than costs, and therefore it is too expensive, overly dominated by technology, too "elitist" and - if one takes

${ }^{23}$ Yarlini Balarajan, Sakthivel Selvaraj, S.V.Subramanian, 'Health Care and Equity in India' (2011) 377 The Lancet 505-515.

${ }^{24}$ Jean Drèze, Amartya Sen, An Uncertain Glory: India and Its Contradictions (Princeton University Press 2013).

${ }^{25}$ Geeta Anand, 'The Henry Ford of Heart Surgery in India', The Wall Street Journal, 25 November 2009.

${ }^{26}$ Jerzy Niemczyk, Strategia. Od planu do sieci (Publishing House of the Wroclaw University of Economics 2013). 
into account the contemporary determinants of providing health care services as described by Callahan - as such, it has no future.

\section{b) Operationalizing innovative solutions}

In 2001, in Bangalore, Karnataka state, Dr. Shetty opened his first clinic, in which he tried to implement solutions that he had familiarized himself with when working in the prestigious and highly modern Guy's Hospital in London. The aim of adopting these solutions was to achieve exceptional value (to increase the quality and accessibility of medical services) while maintaining low prices, i.e. prices that would be low enough to meet demand. This cardiac surgeon did not, however, imitate the British model. On the contrary, he based the functioning of the clinic in Bangalore on negating the rationale behind and eliminating procedures which he had learned about in the UK and which he considered to be unnecessary in the service production process. Dr. Shetty did not create the consumer of medical services (because this consumer had already existed), but he created - from scratch - a system that facilitated access to these services not only for Indians, but also for people from different parts of the world. A chain of 21 clinics was established over a period of 13 years under the name 'Narayana Health'. They were based on the business models used by Henry Ford's production line, the low-cost airlines Ryanair and Air Asia as well as the Japanese car industry ("just in time"). This was possible by initiating informal cooperation with many business partners representing the aforementioned industries in order to identify knowledge which had rarely been put into practice when carrying out medical procedures. In February 2014, Devi Shetty opened Health City Cayman Islands, his first clinic outside of India (104 beds, at a cost of USD 70,000,000). The choice of the Cayman Islands was not accidental. There were two decisive factors at play - proximity to American customers ${ }^{\mathrm{i}}$ and legal regulations.

The specificity of the medical sector is visible in, for example, the way innovations that are undertaken in this sector are perceived. It is mainly open innovation that causes controversy. It is no wonder, then, that there are skeptical opinions about the ideas and the practices that are used in Narayana Health. Comparisons between medical facilities (private or public) and enterprises are clearly treated with reserve, even in the United States where the above approach took shape. The views of C. Phelps, who does not see any difference between producing cars in factories and producing medical services in hospitals ${ }^{27}$, are regarded as a violation of Hippocratic ethics. Role models from the past are associated with deontology. Since the time of the Hippocratic Oath deontology has placed concern for the patient's good, medical confidentiality and care about the authority of the profession at the forefront of a physician's duties. Devi Shetty has not violated any of these principles. However, while using the same information as other participants in this industry, he processed it in a different way and proposed a different strategy, thus providing his customers with new value innovations and creating a blue ocean. Open innovation in his clinics involves selecting ideas which are not new and

${ }^{27}$ Charles E. Phelps, Health Economics (Harper Collins Publishers 1992) 
which were generated by the automotive or aviation industries, and then arranging them in such a configuration that will make it possible to create a new market. He was aware of the differences between the medical and aviation industries and he aptly pointed to the similarities between them. Both industries develop through change. Each aviation accident, even a minor one, contributes to improving the quality and safety of subsequent flights. Similarly, each medical error, even a minor one, contributes to improving the quality and safety of subsequent surgeries. If one wants to function in each of these sectors, one must be aware of the inherent challenges, threats and risks. The concepts of risk in both of these market sectors are related to allocating financial resources and maintaining professional quality.

Dr. Shetty applies a combination of three factors in his clinics: economies of scale, standardization and reduction of costs. He noticed that economies of scale and standardization in medicine translate into the quality of medical procedures. A doctor can only gain experience and specialize in a narrow medical discipline after carrying out a certain number of surgical procedures. Since the physicians at Narayana Health have examined many medical cases and performed many surgeries, they are able to develop skills that are not easily available to physicians in the West. It is no wonder, then, that doctors from around the world want to work and assist in Dr. Shetty's clinics. Colin John, who is one of the world's most respected pediatric cardiac surgeons, performs about $75-80$ operations per month and about 900 operations per year at Narayana Health.

There are 1,000 beds in the clinic in Bangalore, while the average number of beds in a US hospital is 160 , according to data obtained from the American Hospital Association. In 2008, in the Bangalore clinic alone 42 cardiologists performed 3,174 coronary artery bypass surgeries; the costs of one surgery were reduced to 95,000 rupees. Dr. Shetty wants to further reduce these costs by half in the coming years. By contrast, in 2008 a total of 1,367 of such operations were carried out in Cleveland Clinic, in Ohio, USA, a facility specializing in this kind of medical procedures; the price of one treatment was USD 106,385.

\section{c) Benefits of applying innovations in the medical industry}

Currently, Dr. Shetty's cardiology clinic is a part of Narayana Health City in Bangalore. The hospitals, which treat not only heart diseases but also cancer and eye diseases, cover an area of $100,000 \mathrm{~m}^{2}$. In total there are 3,200 beds. The optimal exploitation of infrastructure is one of the ways to maintain low prices. Just as the airplanes operated by low-cost airlines are on the ground for the shortest time possible, operating rooms are used to the maximum extent for six days a week. Doctors perform 2-3 surgeries daily on average, they admit 50-70 patients, and work for about 70 hours a week.

The chain of hospitals uses Web-based software to manage logistics, which is why it is not necessary to buy licenses or establish a separate system for each hospital. At the beginning, Dr. Shetty purchased sutures from Johnson \& Johnson; currently, Centennial Surgical Ltd., which is based in Mumbai, is his supplier. Before this change, the annual cost of ordering sutures was USD 100,000 and was growing by about 5\% a year. After a domestic company was chosen, these expenses were reduced to 
USD 50,000. When negotiations with a European producer leading to a satisfactory price for disposable gowns collapsed, Dr. Shetty persuaded a group of young entrepreneurs from Bangalore to start producing such gowns, and as a result he obtained a $60 \%$ lower price. General Electric is the main supplier of medical equipment. Dr. Shetty wanted to replace this supplier with less expensive Chinese producers, but the Chinese do not have enough potential to ensure continuity of supplies for the clinics, which, apart from Bangalore, also function in such locations as Calcutta, Mysore and Jaipur and carry out $12 \%$ of operations in India, while a given piece of equipment is used 15-20 times a day. The scale of Narayana Health's activity gives it significant bargaining power in negotiations with General Electric, making it possible to obtain significant price reductions. Moreover, Devi Shetty has eliminated unnecessary preoperative testing. For example, urine samples are no longer collected before surgery, because harmful bacteria were detected in very few samples.

Devi Shetty has implemented a radical low-price strategy in the hospital in Mysore. It was designed as a one-story building, which is why it was possible to save on the foundations and lifts. The hospital was constructed from prefabricated components over a period of six months, and the cost of the investment was USD $6,000,000$. The prices of medical procedures there are even lower than in Devi Shetty's other clinics. The cost of uncomplicated heart surgery is USD 1,000, but Dr. Shetty aims to reduce it even more, by half. Patients are placed in wards accommodating 50 people. Only operating rooms and intensive care units are air-conditioned. The austerity policy is so radical that patients' relatives undergo health care training which lasts for more than ten hours in order to be able to perform simple tasks instead of nurses. As a result, the number of medical personnel has been reduced by $10 \%$. Dr. Shetty intends to introduce this model of hospital care in Indian provinces over the next five years by building similar facilities in order to provide medical care to the country's poorest residents.

Apart from revolutionizing the system of hospitals, Shetty has also created Yeshasvini, which is the cheapest health insurance system in the world. This system is modeled on the Grameen Bank solution, which was proposed by the Nobel Peace Prize winner M. Yunus. The poorest farmers can benefit from health care for 10 rupees (about EUR 0.15). In Karnataka state alone more than 3.5 million people use this kind of health insurance.

\section{d) Final conclusions}

The law in a given country reflects its citizens' various beliefs and values, thus creating regulations that establish different standards and impose different requirements on medical entities. Legal provisions and cultural determinants can be barriers to implementing business innovations. Dr. Devi Shetty did not manage to overcome these barriers and he decided to export the model of health care that he had created outside of India in order to be closer to American patients. The US health care system is highly formalized and diversified; the system is complicated, like many other domains, due to the large number of state regulations. This is why the choice of the Cayman Islands - a British overseas territory - as the location for Narayana Health's first foreign clinic was not accidental. The authorities 
there decided to change legal regulations, for example, by eliminating the requirement that doctors' diplomas be validated by Indian medical staff. The medical team at the facility in the Cayman Islands is composed of 70 individuals - physicians, nurses and technicians - and the clinic offers prices that are $30 \%$ lower than those of the US private health care system.

Dr. Shetty has adopted a purely innovative approach to managing his clinics based on the concept of lean management, and which was previously applied in production management (Table 1).

Table 1. Innovation in Narayana Health from a theoretical perspective.

\begin{tabular}{|c|c|c|}
\hline $\begin{array}{l}\text { Innovation } \\
\text { type }\end{array}$ & Strategic function & Narayana Health \\
\hline Values & $\begin{array}{l}\text { going beyond the existing } \\
\text { competition; offering } \\
\text { customers new value that } \\
\text { is not offered by any other } \\
\text { market entity }\end{array}$ & $\begin{array}{l}\text { abandoning the holistic } \\
\text { approach to treatment and } \\
\text { replacing it with a functional } \\
\text { approach }\end{array}$ \\
\hline $\begin{array}{l}\text { Open } \\
\text { innovations }\end{array}$ & $\begin{array}{l}\text { information is obtained } \\
\text { from external sources, as } \\
\text { an input to the process, } \\
\text { and knowledge is } \\
\text { transferred from the } \\
\text { center of the company to } \\
\text { the outside, as a source } \\
\text { for innovative changes for } \\
\text { other entities }\end{array}$ & $\begin{array}{l}\text { using management models } \\
\text { applied by Ford, Ryanair, Air } \\
\text { Asia, the Walmart chain and } \\
\text { Toyota }\end{array}$ \\
\hline $\begin{array}{l}\text { Disruptive } \\
\text { innovations }\end{array}$ & $\begin{array}{l}\text { a tool for implementing } \\
\text { value innovation; a } \\
\text { method for finding new } \\
\text { market space }\end{array}$ & $\begin{array}{l}\text { focusing on cost reduction } \\
\text { rather than on improvements } \\
\text { in existing services - } \\
\text { improving the minimization } \\
\text { of costs instead of improving } \\
\text { treatment processes }\end{array}$ \\
\hline $\begin{array}{l}\text { Lean } \\
\text { innovations }\end{array}$ & $\begin{array}{l}\text { minimizing costs by } \\
\text { slimming down processes } \\
\text { and, consequently, also } \\
\text { costs; an analogy to lean } \\
\text { management }\end{array}$ & $\begin{array}{l}\text { lean services; for example: A } \\
59 \text {-year old American came } \\
\text { to Bangalore in } 2011 \text { because } \\
\text { several doctors in the US had } \\
\text { told him that an operation } \\
\text { would be too risky in his } \\
\text { case. One of them had told } \\
\text { him that he would live } 5 \\
\text { years and the clinic would } \\
\text { charge } 200 \text { thousand dollars } \\
\text { for this medical procedure. } \\
\text { This is why he had started } \\
\text { looking for other } \\
\text { possibilities. He liked the } \\
\text { fact that an Indian surgeon } \\
\text { performs such surgeries } 3 \\
\text { times a day, and not } 3 \text { times } \\
\text { a year like many American }\end{array}$ \\
\hline
\end{tabular}




\begin{tabular}{|l|l|l|}
\hline & & $\begin{array}{l}\text { doctors. The bill for a life- } \\
\text { saving operation that he } \\
\text { received from the Indian } \\
\text { clinic was 19 thousand } \\
\text { dollars }\end{array}$ \\
\hline $\begin{array}{l}\text { Social } \\
\text { innovations }\end{array}$ & $\begin{array}{l}\text { actions for the benefit of } \\
\text { local communities - CSR }\end{array}$ & $\begin{array}{l}\text { clinics providing access to } \\
\text { medical services for the } \\
\text { poorest people }\end{array}$ \\
\hline
\end{tabular}

Source: Own work.

By drawing on the models applied in the companies mentioned above, Devi Shetty has used innovative tools to slim down services in the medical industry, which globally functions according to the paradigm of needs rather than the paradigm of costs.

\section{FURTHER STUDIES AND RESEARCH RESERVATIONS}

Devi Shetty has created a market by eliminating the clash of two types of value, i.e. business and social. This was possible as a result of establishing synergy between three elements. First, benchmarking was used: this allowed him to find a source of innovation in other industries which function based on logic that does not seem suitable for the medical industry. Secondly, Shetty had the courage to negate the paradigm of needs in the medical sector. Thirdly, he was able to build a beneficial cooperation network with different suppliers of products and services. Replication of Narayana Health's model outside of India is problematic. The previously mentioned legal regulations and cultural factors are a barrier to this process; nonetheless, public authorities, especially in Europe, are closely watching the solutions used by the Indians. David Cameron has launched the Dishaa project which is aimed at reducing the costs of cardiac surgery. Devi Shetty is playing a significant role in this process; at the same time, he is conducting talks with authorities in Georgia and Malta about opening a branch based on his business model in these countries. It is worthwhile to ask whether it is possible to introduce such a model in Poland, given the current cultural and legal determinants. It seems that this research issue may provide a basis for further discussions, especially with regard to the need of restructuring the Polish health care system and adopting innovative solutions of a utilitarian nature. 